\title{
Increased breast tissue receptor activator of nuclear factor- KB ligand (RANKL) gene expression is associated with higher mammographic density in premenopausal women
}

\author{
Adetunji T. Toriola ${ }^{1}$, Ha X. Dang ${ }^{2}$, Ian S. Hagemann ${ }^{3}$, Catherine M. Appleton ${ }^{4}$, \\ Graham A. Colditz ${ }^{1}$, Jingqin Luo ${ }^{1}$ and Christopher A. Maher ${ }^{2}$ \\ ${ }^{1}$ Department of Surgery, Division of Public Health Sciences, and Siteman Cancer Center, Washington University School of \\ Medicine, St. Louis, MO, USA \\ ${ }^{2}$ The McDonnell Genome Institute, and Department of Medicine, Washington University, St. Louis, MO, USA \\ ${ }^{3}$ Genomics and Pathology Services, Department of Pathology and Immunology, Washington University School of Medicine, \\ St. Louis, MO, USA \\ ${ }^{4}$ Division of Diagnostic Radiology, Department of Radiology, Washington University School of Medicine, St. Louis, MO, USA
}

Correspondence to: Adetunji T. Toriola, email: a.toriola@wustl.edu

Keywords: mammographic density, breast cancer, RANKL, premenopausal women, prevention

Received: April 12, $2017 \quad$ Accepted: May 01, $2017 \quad$ Published: May 17, 2017

Copyright: Toriola et al. This is an open-access article distributed under the terms of the Creative Commons Attribution License 3.0 (CC BY 3.0), which permits unrestricted use, distribution, and reproduction in any medium, provided the original author and source are credited.

\section{ABSTRACT}

Increased mammographic breast density is associated with a 4-6-fold increased risk of breast cancer, yet lifestyle factors that can reduce dense breasts are yet to be identified, and viable prevention strategies to reduce breast density-associated breast cancer development are yet to be developed. We investigated the associations of breast tissue receptor activator of nuclear factor-KB (RANK) pathway gene expression with mammographic density in $\mathbf{4 8}$ premenopausal women, with no previous history of cancer. Gene expression levels were measured in total RNA isolated from formalinfixed paraffin-embedded breast tissue samples, using the NanoString nCounter platform. Mammographic density was classified based on the American College of Radiology Breast Imaging Reporting and Data (BI-RADS). Linear regression was used to evaluate associations between gene expression and mammographic density. The mean age of participants was $\mathbf{4 4 . 4}$ years. Women with higher breast tissue RANKL $($ TNFSF11 $)(p$-value $=0.0076)$, and TNF $(p$-value $=0.007)$ gene expression had higher mammographic density. Our finding provides mechanistic support for a breast cancer chemoprevention trial with a RANKL inhibitor among high-risk premenopausal women with dense breasts.

\section{INTRODUCTION}

Increased mammographic breast density is associated with a 4-6-fold increased risk of breast cancer [1-3]. Each 1\% increase in percent mammographic density is associated with a $3 \%$ increase in breast cancer risk among women using estrogen plus progestin [1]. Estimates of attributable risk suggest that having dense breasts may account for $28-33 \%$ of breast cancer cases [4]. Furthermore, 2.4 million premenopausal women in the United States have extremely dense breasts [5]. Hence, providing targeted prevention to these women could have a major impact on reducing breast cancer incidence.
Nevertheless, lifestyle factors that can reduce dense breasts are yet to be identified, and viable prevention strategies to reduce mammographic breast density-associated breast cancer development are yet to be developed.

Preclinical studies demonstrating important functional roles for the receptor activator of nuclear factor$\kappa \mathrm{B}$ (RANK) pathway, a member of the tumor necrosis factor (TNF) superfamily in breast development suggest that targeting this pathway could have utility in primary breast cancer prevention. RANK is the signaling receptor for RANK ligand (RANKL), while osteoprotegerin (OPG) acts as a soluble decoy receptor [6]. RANKL is required for mammary epithelial cell proliferation [7], 
an essential part of breast density. Seminal experimental studies revealed that RANKL signaling mediates the major proliferative response of mammary epithelium to progesterone, and progesterone-driven expansion of mammary stem cells $[8,9]$. Progesterone is a breast mitogen; it increases breast density, and is a risk factor for breast cancer, independent of estrogen [10, 11]. Notably, disruption of RANKL signaling attenuates progestindriven mammary epithelial cell proliferation, and reduces the onset of mammary tumors in experimental studies $[7,8,12]$. In addition, novel data show that RANKL signaling could be important in BRCA1 mutation-driven mammary cancer [13], and RANKL inhibition in breast organoids derived from pre-neoplastic BRCA mutation tissue attenuated progesterone-induced proliferation $[13,14]$. Therefore, targeting RANKL signaling could present a path to reducing mammographic breast density, as well as breast-density associated breast cancer development. However, to the best of our knowledge, no study has evaluated how RANKL signaling influences mammographic density. Here, we investigated for the first time the associations of breast tissue $R A N K$ pathway gene expression with mammographic density in premenopausal women.

\section{RESULTS}

The mean age of women in our study was 44.4 years (Table 1). The mean body mass index (BMI) was $27.5 \mathrm{~kg} / \mathrm{m}^{2}$. In line with the mammographic density distribution among US women, the majority of women
$(\mathrm{N}=20,41.7 \%)$ in our study had heterogeneously dense breasts, $18(37.5 \%)$ had scattered areas of fibroglandular density and $9(18.8 \%)$ had extremely dense breasts. We observed statistically significant associations between breast tissue RANKL (TNFSF11) and TNF gene expression and mammographic density, but no statistically significant associations between breast tissue expression of other genes (e.g. CYP27A1, EGFR, ESR1, IGF-1, IGFBP-3, IL$\sigma)$ and mammographic density (Figure 1A). Women with higher breast tissue $R A N K L$ (TNFSF 11) ( $p$-value=0.0076), and $T N F$ ( $p$-value $=0.007)$ gene expression had higher mammographic density (Figure $1 \mathrm{~B}$ and $1 \mathrm{C}$ ). Findings were similar in sensitivity analyses ( $P$-value for $R A N K L$ gene expression was 0.012) where we re-categorized the women into lower mammographic density and higher mammographic density.

\section{DISCUSSION}

We provide the first evidence showing that $R A N K L$ gene expression is associated with mammographic density in premenopausal women. Our finding has translational potentials, and provides additional context on targeting RANKL signaling in breast cancer prevention. Recent data showing that RANKL signaling may drive BRCA1 mutation driven mammary cancer has generated interest in targeting RANKL inhibition for chemoprevention in women with BRCA1 mutation. A dense breast on mammogram confers similar magnitude of risk (i.e. 4-6 fold) as BRCA1 mutation [15]. Importantly, breast cancer risk decreases among women whose mammographic
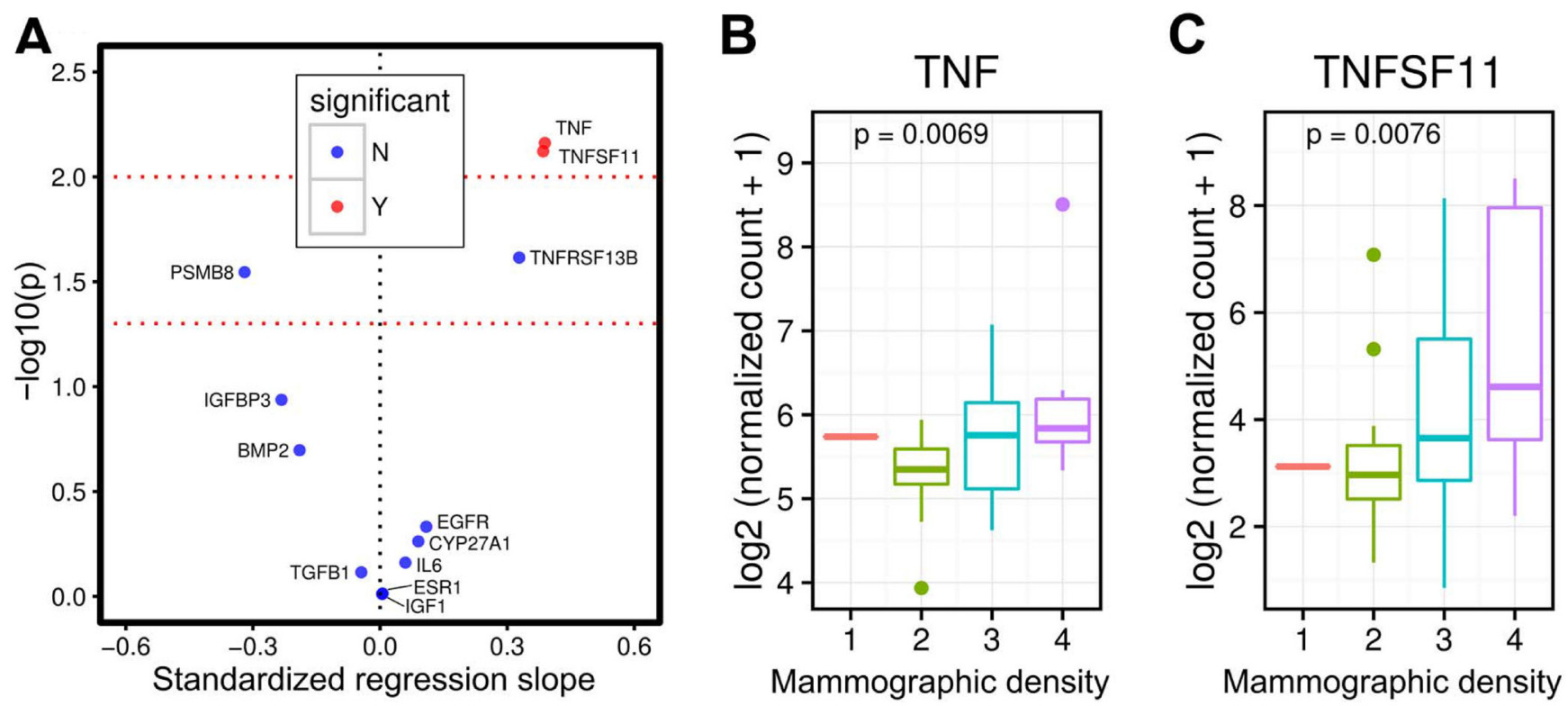

Figure 1: Breast tissue TNFSF11 (RANKL) and TNF gene expression and mammographic density in premenopausal women. Volcano plot showing that breast tissue TNFSF11 (RANKL) and TNF gene expression are associated with mammographic density in premenopausal women, but not gene expression of other proteins (e.g. IGF1, EGFR) (A) Figures showing that higher breast tissue RANKL $($ TNFSF11, $p$-value $=0.0076)$ and TNF $(p$-value $=0.0069)$ gene expression are associated with higher mammographic density in premenopausal women (B and $\mathbf{C})$. 
Table 1: Characteristics of $\mathbf{4 8}$ premenopausal women from the St. louis breast tissue registry who provided breast tissue and mammographic density data

\begin{tabular}{|c|c|}
\hline & Mean (Standard deviation) \\
\hline Age, years & $44.38(4.0)$ \\
\hline \multirow[t]{2}{*}{ Body Mass Index, $\mathrm{kg} / \mathrm{m}^{2}$} & $27.45(5.9)$ \\
\hline & Number of observations (\%) \\
\hline \multicolumn{2}{|l|}{ Race } \\
\hline White Non-Hispanic & $33(68.8)$ \\
\hline African American & $12(25.0)$ \\
\hline Others & $3(6.2)$ \\
\hline \multicolumn{2}{|l|}{ Mammographic density } \\
\hline 1 & $1(2.1)$ \\
\hline 2 & $18(37.5)$ \\
\hline 3 & $20(41.7)$ \\
\hline 4 & $9(18.8)$ \\
\hline
\end{tabular}

density decreased over time compared to women whose density stayed the same [16]. Therefore, RANKL inhibition with denosumab could be a viable breast cancer prevention strategy in high-risk premenopausal women [17] with dense breasts.

RANKL signaling regulates the development of the lobulo-alveolar mammary structures during pregnancy and the formation of lactating mammary glands [18-20]. RANK overexpression in the mammary epithelia impairs alveolar differentiation and lactation [21]. RANK and RANKL knock out mice display a complete defect in the formation of lactating mammary glands, due to decreased proliferation and survival of mammary epithelial cell, similar to that observed in progesterone receptor B knockout mice [18, 22, 23]. RANKL signaling also activates downstream signaling cascades such as NF-kB and cyclin D1 [6, 12], which are key pathways, involved in breast cancer development $[6,12]$. Very recent studies conducted in Europe demonstrated that elevated serum RANKL levels are associated with increased breast cancer risk among women with high progesterone levels [24], while another study reported that elevated OPG levels are associated with increased breast cancer risk [25]. Our study adds to findings from these initial studies indicating that the RANK pathway plays an important role in breast cancer development.

Besides being a strong risk factor for breast cancer, mammographic density and breast cancer share similar biological and genetic pathways [26, 27]. Thus, being a strong intermediate phenotype for breast cancer provides additional support for targeting women with dense breasts in breast cancer chemoprevention. Mammographic density is highly heritable, with suggestion that genetic factors may explain $60 \%$ of the variance [28]. Nevertheless, the loci identified to date explain $<3 \%$ of the variance in mammographic density [27, 29] indicating that many genetic determinants are yet to be identified. Although some known breast cancer susceptibility loci are also associated with mammographic density [27], mutations in highly penetrant breast cancer genes; BRCA1 and BRCA 2 genes have not been found to be associated with mammographic density [30].

Aside from reproductive factors and alcohol consumption, most of the other lifestyle factors that can be modified to reduce breast cancer risk (e.g. obesity, menopausal hormone use) are only relevant to disease among postmenopausal women. Likewise, adult diet is not related to mammographic density [31], hence, dietary and lifestyle modifications are not likely to impact mammographic density. Tamoxifen is the only approved chemoprevention agent in premenopausal women, but uptake is very low due to risk of serious side effects $[32,33]$. Therefore, denosumab could be a more attractive chemoprevention option in high-risk premenopausal women because of its safety profile [34]. It is currently in clinical use for the management of osteoporosis and for preventing bone loss, as well as fractures associated with cancer therapies and bone metastases [34], whereas tamoxifen negatively impacts bone health in premenopausal women [35]. Further, unlike tamoxifen, which must be taken daily, denosumab is typically given every six months [34]. Hence, chemoprevention with denosumab might require administration every 6 months, which should considerably help improve compliance.

In conclusion, findings from our study provide essential mechanistic support for targeting RANKL signaling in reducing breast cancer development in highrisk premenopausal women with dense breasts. 


\section{MATERIALS AND METHODS}

\section{Study population}

We identified 48 premenopausal women, with no previous history of cancer, who had a screening mammogram and subsequent breast biopsy at the Joanne Knight Breast Health Center, Washington University School of Medicine (WUSM), St. Louis, MO between December 2008 and 2015, and afterwards had their breast tissue samples stored in the well-annotated St. Louis Breast Tissue Registry (SLBTR), Department of Surgery, WUSM. The SLBTR was created in 1993 as part of the National Cancer Institute (NCI) Cooperative Breast Cancer Tissue Resource. It maintains a publicly available supply of archival breast tissue specimens coupled with clinical, pathological, and follow-up data from five hospitals in the St. Louis region. Breast tissue specimens were evaluated for pathologic diagnosis by breast pathologists using standard diagnostic criteria. Eligibility criteria for our study included (i) women must be premenopausal at the time of mammogram; (ii) no history of ovariectomy (ii) no evidence of cancer on breast biopsy, (iii) breast biopsy must have been done within 30 days of having a mammogram. Exclusion criteria were (i) history of any cancer, (ii) selective estrogen receptor modulator, aromatase inhibitors, or bisphosphonates use within 6 months of having a mammogram, (iii) history of breast implants, reduction mammoplasty, or augmentation.

\section{RANK pathway gene expression}

Gene expression levels were measured in total RNA isolated from formalin-fixed paraffin-embedded (FFPE) breast tissue samples, using the NanoString nCounter platform. We selected this platform because it reliably monitors gene expression in archival specimens, has technical reproducibility, and allows direct measurement of RNA expression levels without enzymatic reactions or bias. In addition to $R A N K L$ gene, we also targeted known genes in TNF superfamily such as TNF and TNFRSF13B. We designed nanoString probes to monitor gene expression of additional genes (such as CYP27A1, EGFR, ESR 1, IGF-1,IGFBP-3,IL-6) that may be related to breast cancer risk. Gene expression was performed at the McDonnell Genome Institute (MGI), WUSM. Digital transcript counts from the NanoString nCounter assay was normalized using the housekeeping genes (ACTB, RPLPO, and $S F 3 A 1$ ) following the manufacturer's guidelines.

\section{Mammographic density assessment}

Mammographic density was classified based on the American College of Radiology Breast Imaging Reporting and Data (BI-RADS) system as (i) Almost entirely fatty, (ii)
Scattered areas of fibroglandular density, (iii) Heterogeneously dense, (iv) Extremely dense. In sensitivity analyses, we categorized the women into 2 groups; lower mammographic density group (entirely fatty breast and scattered areas of fibroglandular patterns), and higher mammographic density group (heterogeneously dense and extremely dense).

\section{Statistical analyses}

NanoString nCounter transcript counts were normalized to the positive spike-in control probes, and subsequently to the housekeeping genes ( $A C T B, R P L P O$, and $S F 3 A 1)$. Background was measured by negative spike-in controls. For each sample, a geometric mean of the counts of housekeeping genes was calculated. The average of the housekeeping geometric means across samples was also calculated and then divided by each sample's housekeeping genes' geometric mean to obtain the scaling factor for the corresponding sample. A gene was considered to be expressed if its normalized count was higher than the mean normalized count of the negative control probes in at least 10 samples. Normalized counts were $\log$ transformed prior to downstream analysis. A linear regression was used to evaluate associations between gene expression and mammographic density. All analyses and visualizations were performed in R software version 3.1.2.

\section{ACKNOWLEDGMENTS AND FUNDING}

The study is supported by funds from the Susan G. Komen Foundation (CCR15332379 - ATT), Siteman Cancer Center Siteman Investment Program (supported by The Foundation for Barnes-Jewish Hospital Cancer Frontier Fund (BJFH CFF 3781 \& 4035); NCI Cancer Center Support Grant (P30 CA091842); Fashion Footwear Charitable Foundation of New York, Inc.; Barnard Trust; and, the Siteman Discovery Fund), Siteman Cancer Center Biostatistics Shared Resource, and Washington University School of Medicine. The Siteman Cancer Center is supported in part by an NCI Cancer Center Support Grant \#P30 CA091842. I.S.H. is supported by NIH R25 CA190190. We thank Mr. Thomas Walsh, Research Lab Supervisor for the St. Louis Breast Tissue Registry for project management.

\section{CONFLICTS OF INTEREST}

The authors disclose no potential conflicts of interest

\section{REFERENCES}

1. Byrne C, Ursin G, Martin CF, Peck JD, Cole EB, Zeng D, Kim E, Yaffe MD, Boyd NF, Heiss G, McTiernan A, Chlebowski RT, Lane DS, et al. Mammographic Density Change With Estrogen and Progestin Therapy and Breast Cancer Risk. J Natl Cancer Inst. 2017; 109. 
2. Pettersson A, Graff RE, Ursin G, Santos Silva ID, McCormack V, Baglietto L, Vachon C, Bakker MF, Giles GG, Chia KS, Czene K, Eriksson L, Hall P, et al. Mammographic density phenotypes and risk of breast cancer: a meta-analysis. J Natl Cancer Inst. 2014; 106.

3. Boyd NF, Guo H, Martin LJ, Sun L, Stone J, Fishell E, Jong RA, Hislop G, Chiarelli A, Minkin S, Yaffe MJ. Mammographic density and the risk and detection of breast cancer. N Engl J Med. 2007; 356:227-36.

4. Boyd NF, Rommens JM, Vogt K, Lee V, Hopper JL, Yaffe MJ, Paterson AD. Mammographic breast density as an intermediate phenotype for breast cancer. Lancet Oncol. 2005; 6:798-808.

5. Sprague BL, Gangnon RE, Burt V, Trentham-Dietz A, Hampton JM, Wellman RD, Kerlikowske K, Miglioretti DL. Prevalence of mammographically dense breasts in the United States. J Natl Cancer Inst. 2014; 106:106.

6. Hanada R, Hanada T, Penninger JM. Physiology and pathophysiology of the RANKL/RANK system. Biol Chem. 2010; 391:1365-70.

7. Beleut M, Rajaram RD, Caikovski M, Ayyanan A, Germano D, Choi Y, Schneider P, Brisken C. Two distinct mechanisms underlie progesterone-induced proliferation in the mammary gland. Proc Natl Acad Sci USA. 2010; 107:2989-94.

8. Schramek D, Leibbrandt A, Sigl V, Kenner L, Pospisilik JA, Lee HJ, Hanada R, Joshi PA, Aliprantis A, Glimcher L, Pasparakis M, Khokha R, Ormandy CJ, et al. Osteoclast differentiation factor RANKL controls development of progestin-driven mammary cancer. Nature. 2010; 468:98-102.

9. González-Suárez E. RANKL inhibition: a promising novel strategy for breast cancer treatment. Clin Transl Oncol. 2011; 13:222-28.

10. Beral V, Banks E, Reeves G, Bull D, and Million Women Study Collaborators. Breast cancer and hormonereplacement therapy in the Million Women Study. Lancet. 2003; 362:419-27.

11. Rossouw JE, Anderson GL, Prentice RL, LaCroix AZ, Kooperberg C, Stefanick ML, Jackson RD, Beresford SA, Howard BV, Johnson KC, Kotchen JM, Ockene J, and Writing Group for the Women's Health Initiative Investigators. Risks and benefits of estrogen plus progestin in healthy postmenopausal women: principal results From the Women's Health Initiative randomized controlled trial. JAMA. 2002; 288:321-33.

12. Gonzalez-Suarez E, Jacob AP, Jones J, Miller R, RoudierMeyer MP, Erwert R, Pinkas J, Branstetter D, Dougall WC. RANK ligand mediates progestin-induced mammary epithelial proliferation and carcinogenesis. Nature. 2010; 468:103-07.

13. Sigl V, Owusu-Boaitey K, Joshi PA, Kavirayani A, Wirnsberger G, Novatchkova M, Kozieradzki I, Schramek D, Edokobi N, Hersl J, Sampson A, Odai-Afotey A, Lazaro $\mathrm{C}$, et al. RANKL/RANK control Brcal mutation-driven mammary tumors. Cell Res. 2016; 26:761-74.
14. Nolan E, Vaillant F, Branstetter D, Pal B, Giner G, Whitehead L, Lok SW, Mann GB, Rohrbach K, Huang LY, Soriano R, Smyth GK, Dougall WC, et al, and Kathleen Cuningham Foundation Consortium for Research into Familial Breast Cancer (kConFab). RANK ligand as a potential target for breast cancer prevention in BRCA1mutation carriers. Nat Med. 2016; 22:933-39.

15. American Cancer Society. Breast Cancer Facts and Figures 2011-2012. Atlanta: American Cancer Society, Inc. 2012.

16. Kerlikowske K, Ichikawa L, Miglioretti DL, Buist DS, Vacek PM, Smith-Bindman R, Yankaskas B, Carney PA, Ballard-Barbash R, and National Institutes of Health Breast Cancer Surveillance Consortium. Longitudinal measurement of clinical mammographic breast density to improve estimation of breast cancer risk. J Natl Cancer Inst. 2007; 99:386-95.

17. The National Comprehensive Cancer Network. NCCN Clinical Practice Guidelines in Oncology. Breast Cancer. 2011.

18. Fata JE, Kong YY, Li J, Sasaki T, Irie-Sasaki J, Moorehead RA, Elliott R, Scully S, Voura EB, Lacey DL, Boyle WJ, Khokha R, Penninger JM. The osteoclast differentiation factor osteoprotegerin-ligand is essential for mammary gland development. Cell. 2000; 103:41-50.

19. Asselin-Labat ML, Vaillant F, Sheridan JM, Pal B, Wu D, Simpson ER, Yasuda H, Smyth GK, Martin TJ, Lindeman GJ, Visvader JE. Control of mammary stem cell function by steroid hormone signalling. Nature. 2010; 465:798-802.

20. Joshi PA, Jackson HW, Beristain AG, Di Grappa MA, Mote PA, Clarke CL, Stingl J, Waterhouse PD, Khokha R. Progesterone induces adult mammary stem cell expansion. Nature. 2010; 465:803-07.

21. Fernandez-Valdivia R, Mukherjee A, Ying Y, Li J, Paquet M, DeMayo FJ, Lydon JP. The RANKL signaling axis is sufficient to elicit ductal side-branching and alveologenesis in the mammary gland of the virgin mouse. Dev Biol. 2009; 328:127-39.

22. Sigl V, Penninger JM. RANKL/RANK - from bone physiology to breast cancer. Cytokine Growth Factor Rev. 2014; 25:205-14.

23. Mulac-Jericevic B, Lydon JP, DeMayo FJ, Conneely OM. Defective mammary gland morphogenesis in mice lacking the progesterone receptor B isoform. Proc Natl Acad Sci USA. 2003; 100:9744-49.

24. Kiechl S, Schramek D, Widschwendter M, Fourkala EO, Zaikin A, Jones A, Jaeger B, Rack B, Janni W, Scholz C, Willeit J, Weger S, Mayr A, et al. Aberrant regulation of RANKL/OPG in women at high risk of developing breast cancer. Oncotarget. 2017; 8:3811-25. https://doi. org/10.18632/oncotarget.14013.

25. Fortner RT, Sarink D, Schock H, Johnson T, Tjønneland A, Olsen A, Overvad K, Affret A, His M, Boutron-Ruault MC, Boeing H, Trichopoulou A, Naska A, et al. Osteoprotegerin and breast cancer risk by hormone receptor subtype: a nested case-control study in the EPIC cohort. BMC Med. 2017; 15:26. 
26. Varghese JS, Thompson DJ, Michailidou K, Lindström S, Turnbull C, Brown J, Leyland J, Warren RM, Luben RN, Loos RJ, Wareham NJ, Rommens J, Paterson AD, et al, and MODE Consortium. Mammographic breast density and breast cancer: evidence of a shared genetic basis. Cancer Res. 2012; 72:1478-84.

27. Lindström S, Thompson DJ, Paterson AD, Li J, Gierach GL, Scott C, Stone J, Douglas JA, dos-Santos-Silva I, Fernandez-Navarro P, Verghase J, Smith P, Brown J, et al. Genome-wide association study identifies multiple loci associated with both mammographic density and breast cancer risk. Nat Commun. 2014; 5:5303.

28. Boyd NF, Dite GS, Stone J, Gunasekara A, English DR, McCredie MR, Giles GG, Tritchler D, Chiarelli A, Yaffe MJ, Hopper JL. Heritability of mammographic density, a risk factor for breast cancer. N Engl J Med. 2002; 347:886-94.

29. Lindström S, Vachon CM, Li J, Varghese J, Thompson D, Warren R, Brown J, Leyland J, Audley T, Wareham NJ, Loos RJ, Paterson AD, Rommens J, et al. Common variants in ZNF365 are associated with both mammographic density and breast cancer risk. Nat Genet. 2011; 43:185-87.

30. Mitchell G, Antoniou AC, Warren R, Peock S, Brown J, Davies R, Mattison J, Cook M, Warsi I, Evans DG, Eccles D, Douglas F, Paterson J, et al. Mammographic density and breast cancer risk in BRCA1 and BRCA2 mutation carriers. Cancer Res. 2006; 66:1866-72.
31. Tamimi RM, Colditz GA, Hankinson SE. Circulating carotenoids, mammographic density, and subsequent risk of breast cancer. Cancer Res. 2009; 69:9323-29.

32. Waters EA, McNeel TS, Stevens WM, Freedman AN. Use of tamoxifen and raloxifene for breast cancer chemoprevention in 2010. Breast Cancer Res Treat. 2012; 134:875-80.

33. Cuzick J, Powles T, Veronesi U, Forbes J, Edwards R, Ashley S, Boyle P. Overview of the main outcomes in breast-cancer prevention trials. Lancet. 2003; 361:296-300.

34. Lacey DL, Boyle WJ, Simonet WS, Kostenuik PJ, Dougall WC, Sullivan JK, San Martin J, Dansey R. Bench to bedside: elucidation of the OPG-RANK-RANKL pathway and the development of denosumab. Nat Rev Drug Discov. 2012; 11:401-19.

35. Powles TJ, Hickish T, Kanis JA, Tidy A, Ashley S. Effect of tamoxifen on bone mineral density measured by dualenergy x-ray absorptiometry in healthy premenopausal and postmenopausal women. J Clin Oncol. 1996; 14:78-84. 